\title{
SHOSHANA FELMAN
}

\section{KARINE DE MEDEIROS RIBEIRO ${ }^{1}$}

\author{
Universidade Estadual de Campinas - UNICAMP
}

Cidade Universitária Zeferino Vaz - Barão Geraldo, Campinas - SP, 13083-970

karinedemedeirosribeiro52617@gmail.com

[...] Eu gostaria de escrever de tal maneira que, para um observador de fora, seria impossível dizer se sou uma francesa escrevendo sobre a América, ou se eu sou uma americana escrevendo sobre a França. (De fato, eu não sou nem francesa, nem americana.). (FELMAN, [1977] 2020a, p. 45)

Em uma entrevista com Cathy Caruth, Shoshana Felman afirma que o seu trauma era o de "não se sentir em casa em nenhuma língua estrangeira, tampouco em sua língua materna, mas de encontrar finalmente o seu lugar na escrita. 'Minha escrita é meu país' - ela diria, conferindo um lugar central em sua vida” (BRANCO, 2020, p. 9).

Nascida em Israel, a produção dessa autora transita entre línguas (a francesa e a inglesa), continentes, países e disciplinas, apesar de a literatura se constituir como objeto privilegiado de seus estudos. Ela estudou na Universidade de Grenoble e lecionou de 1970 a 2004 na Universidade de Yale. Atualmente, é professora de Literatura Comparada na universidade de Emory.

De acordo com Lucia Castello Branco (2020; 2021), Shoshana Felman morou na França aos dezenove anos e lá escreveu uma dissertação orientada por Jean Starobinski. Pouco tempo depois, conheceu Jacques Lacan, que logo se tornou uma referência fundamental para ela. Em depoimento, a autora conta que seu primeiro encontro com Lacan aconteceu em 1971, durante suas férias de primavera em Paris. Admiradora dos Escritos, ela assistiu a uma releitura do "Seminário sobre "A carta roubada" " $2 \mathrm{e}$ percebeu uma ressonância entre o texto de Lacan e a sua tese recém-defendida sobre Stendhal. Após a aula, ela abordou o psicanalista, que ficou impressionado com as semelhanças entre as suas leituras. É importante ressaltar que a psicanálise lacaniana embasou outros estudos da autora, como a sua análise de $A$ Volta do Parafuso, de Henry James. Este é, até hoje, um dos estudos mais relevantes que envolvem a relação entre literatura e psicanálise.

Outro autor que influenciou os seus trabalhos foi Paul de Man, um dos principais teóricos da "escola de Yale". Operando na tensão entre retórica e gramática, o autor trouxe, para o primeiro campo, as teorias do performativo de John Austin. O próprio

\footnotetext{
${ }^{1}$ Doutora em Linguística pela Universidade Estadual de Campinas. Pesquisadora dos seguintes grupos: PsiPoliS, Mulheres em Discurso e CoLHIBri.

${ }^{2}$ Contudo, foi somente em 1974, quando passou um ano sabático em Paris, que conseguiu assistir $O$ Seminário de Lacan ("Les non-dupes errent"), de forma consecutiva e regular.
} 
conceito de "performativo", no entanto, não é "importado para essa teoria como tal, mas encontra-se, ele mesmo, deslocado, modificado e repensado, em particular por meio da filosofia de Nietzsche" (FELMAN, [1977] 2020a p. 51). Esse novo modo de ler a teoria de Austin foi crucial para a interpretação adotada por Shoshana Felman no livro Le Scandale du corps parlant : Don Juan avec Austin, ou la Séduction on deux langues (1980). Se a noção de performativo de Paul de Man é essencial à sua obra, a abordagem de Shoshana Felman, por sua vez, deu base para autoras como Judith Butler e Eve Sedgwick.

O livro Testimony: Crises of Witnessing in Literature, Psychoanalysis and History (1992), escrito em coautoria com Dori Laub, é considerado um ponto de virada em sua trajetória acadêmica (FELMAN, 2003). A partir desse trabalho, a autora se voltou também para os estudos sobre trauma e testemunho. No prefácio da edição brasileira de $O$ inconsciente jurídico: Julgamentos e traumas no século $X X$, Márcio Seligmann-Silva (2014, p. 7) afirma que, assim como Cathy Caruth, ela é "uma das principais responsáveis pelo estabelecimento dos 'estudos do trauma' que até hoje têm multiplicado de modo muito criativo a leitura e a interpretação de fenômenos culturais".

\section{Márcio Seligmann-Silva a define como}

uma das críticas e teóricas da literatura mais influentes do panorama atual. Sua obra vem inspirando diversos autores e apontando para novas abordagens da literatura e da cultura de um modo geral, nas quais ela faz convergir seu erudito saber literário e filológico com seu competente domínio da psicanálise, dialogando ainda, [...], de modo muito competente, com os estudos jurídicos. (SELIGMANN-SILVA, 2000, p. 7)

Essa citação indica tanto a relevância da autora quanto a sua multiplicidade, interessando a diferentes disciplinas e campos. Apesar de ser uma das mais profícuas teóricas da atualidade, ela ainda é pouco traduzida no Brasil (BRANCO, 2020).

A seguir, enumero suas principais obras de acordo com o ano de publicação:

- La "Folie" dans l'œuvre romanesque de Stendhal (1971);

- $\quad$ La Folie et la chose littéraire (1978);

- $\quad$ Le Scandale du corps parlant : Don Juan avec Austin, ou la Séduction on deux langues (1980);

- $\quad$ The Literary Speech Act: Don Juan with Austin, or Seduction in Two Languages (1984) (primeira tradução para a língua inglesa de Le Scandale du corps parlant);

- $\quad$ Writing and Madness: Literature/Philosophy/Psychoanalysis (1985);

- Jacques Lacan and the adventure of insight: Psychoanalysis in contemporary culture (1987);

- Testimony: Crises of Witnessing in Literature, Psychoanalysis and History (1992), em coautoria com Dori Laub;

- What Does a Woman Want? Reading and Sexual Difference (1993);

- $\quad$ The Scandal of the Speaking Body: Don Juan with Austin, or Seduction

in Two Languages (2002), (segunda tradução para a língua inglesa de Le Scandale du corps parlant, com posfácio de Judith Butler); 
- $\quad$ The Juridical Unconscious: Trials and Traumas in the Twentieth Century (2002);

- Writing and Madness: Literature/Philosophy/Psychoanalysis (2003) (segunda edição, trazendo em apêndice entrevistas com Jacques-Alain Miller e Philippe Sollers;

- $\quad$ The Claims of Literature: The Shoshana Felman Reader (2007).

Alguns trabalhos da autora foram traduzidos para português:

- $\quad$ Educação e crise, ou as vicissitudes do ensino (2000) $)^{3}$. O ensaio integra o livro Catástrofe e representação, organizado por Arthur Nestrovski e MárcioSeligmann-Silva;

- Sobrevivência postal, ou a questão do umbigo (2012), traduzido por Flavia Trocoli e Suely Aires para a revista Terceira Margem ${ }^{4}$;

- $\quad$ O inconsciente jurídico: julgamentos e traumas no século XX (2014);

- Shoshana Felman e a coisa literária: escrita, loucura, psicanálise (2020), organizado por Lucia Castello Branco.

Farei um breve percurso por trabalhos significativos da autora, discutindo os principais temas por ela abordados.

Uma das maiores contribuições de Shoshana Felman são os seus ensaios sobre a relação entre loucura e literatura e, consequentemente, a coisa literária.

Esses ensaios podem ser encontrados em La folie et la chose litérarie (1978); nas duas edições de língua inglesa de Writing and Madness (1985; 2003) e, atualmente, na versão brasileira Shoshana Felman e a coisa literária $(2020)^{5}$.

Em "The story of the book seen retrospectively: Preface to the new edition", texto feito para a segunda edição de Writing and Madness, ela afirma que o livro surgiu em um período de grande efervescência da intelectualidade parisiense. A (re)escrita, seleção, reformulação e (re)estruturação para as versões inglesas não ocorreram de forma simplista, como mera transposição de uma língua à outra. De acordo com a autora, a tradução é um processo complexo que marca a sua experiência com as diferentes línguas, "uma operação, um modo de funcionamento para se pensar tanto a 'loucura' quanto a coisa literária" (BRANCO, 2020, p. 27). Não é casual, portanto, que Shoshana Felman interrogue: "Falar da loucura — em que língua?".

\footnotetext{
${ }^{3}$ Ensaio primeiramente lançado na American Imago n. 48 (1991) e posteriormente reeditado, alterado e publicado no livro Testimony: Crises of Witnessing in Literature, Psychoanalysis, and History (1992), de Shoshana Felman e Dori Laub. Há ainda uma terceira versão do texto que saiu em Trauma. Explorations in Memory, livro introduzido e editado por Cathy Caruth (1995). A tradução brasileira deriva deste último texto.

${ }^{4}$ Tradução de "Postal survival, or question of the navel” (1985), da Yale French Studies, n. 69.

${ }^{5}$ Com base na versão francesa e nas estadunidenses, a recente edição de Lucia Castello Branco recolheu os textos significativos do trabalho da autora. Alguns dos ensaios encontrados em La folie et la chose litérarie (1978) e em Writing and Madness: Literature/Philosophy/ Psychoanalysis (1985; 2020) são excluídos da versão brasileira, a exemplo dos capítulos sobre Honoré de Balzac e Gérard de Nerval. Contudo, há a inclusão de um ensaio sobre Arthur Rimbaud que só existia na edição francesa.
} 
A essência do recalcamento é definida por Freud como um "defeito de tradução", ou seja, como a própria barreira que nos separa de uma língua estrangeira. Ou, se a loucura, como a coisa literária, é regida por aquilo mesmo que a recalca, por aquilo mesmo que a inter-diz na língua; se ambas procedem, de alguma forma, de uma e de outra, e cada uma à sua maneira, de um "defeito de tradução", o projeto de lêlas deve necessitar de uma passagem entre as línguas. (FELMAN, [1977] 2020a, p. 46).

Além de a tradução ser problematizada enquanto um modo de funcionamento específico, o conceito fundamental manejado para discutir a relação entre literatura e loucura é o que ela nomeia de coisa literária. Coisa literária é um conceito definido pela autora a partir de noções extraídas de vários campos, como a psicanálise, a literatura e a filosofia. Nesse sentido, Lucia Castello Branco chama a atenção para o modo como Lacan nomeou o "das Ding" de Sigmund Freud como a "Coisa Freudiana". Além disso, Shoshana Felman se apoiou ainda nas leituras de Martin Heidegger, Jacques Derrida e Maurice Blanchot. Este último, em "A literatura e o direito à morte", escreveu a expressão "Coisa literária", em referência direta à grafia maiúscula da "Coisa freudiana". Felman busca "conferir autonomia à coisa literária [grafado em minúsculo], não a subordinando à atividade do escritor e tampouco à especificidade da literatura".

Se a literatura, de seu lugar específico, nos ensina sobre a loucura, a loucura pode, por sua vez, nos ensinar sobre a coisa literária? Pareceme que, se existe de fato alguma coisa como a coisa literária, ela não se dá, como se pôde pensar, em virtude de uma "sublimação", ou de uma função propriamente terapêutica da escrita, mas em virtude de uma irredutível resistência da coisa à interpretação. A loucura, em última instância, será definida neste livro como uma resistência em ato à interpretação. (FELMAN, [1977] 2020b, p. 295, grifo da autora).

A resistência da coisa à interpretação é exemplarmente analisada no ensaio sobre $A$ Volta do Parafuso, de Henry James. Mesmo não havendo uma menção explícita à expressão "coisa literária", temos nessa leitura uma mostração do seu funcionamento (BRANCO, 2020). "A volta do parafuso coloca em ato a própria história da leitura, enquanto ela subverte o leitor. Acreditando dominar, compreender a história, é a história que nos compreende, nos toma" (FELMAN, [1976/1977] 2020, p. 257).

A autora chama a atenção na "armadilha para a psicanálise" que Henry James ${ }^{6}$. constrói para o leitor que não querendo bancar o bobo, é enganado ao tentar dominar os sentidos do texto, tal como acontece na leitura "freudiana" de Edmund Wilson. Em 1934, Wilson propôs outra chave de leitura de A Volta do Parafuso, não a considerando uma história de fantasmas, como era a interpretação corrente da obra, mas uma história de loucura. Para o autor, "os fantasmas não teriam existência objetiva, sendo, antes, os

\footnotetext{
${ }^{6}$ A história de A Volta do Parafuso acompanha uma jovem governanta encarregada de cuidar de duas crianças órfãs (Miles e Flora), que viviam em uma casa isolada no campo. Após a expulsão do menino da escola sem maiores explicações, a governanta começa a ver fantasmas. Acreditando ser os espíritos de dois antigos empregados da casa, Peter Quint e Srta. Jessel, ela acredita que os fantasmas estão corrompendo as crianças. Buscando salvar os dois órfãos, ela tenta forçar a confissão sobre as assombrações. A menina recusa a ser confessar e adoece. Já o menino sob pressão "confessa" o nome de Peter Quint e morre imediatamente nos braços da governanta, no momento em que "ela o abraça, para celebrar sua vitória moral. É sobre esse abraço apaixonado no cadáver, trágica e pateticamente irônico, que a narrativa se fecha" (FELMAN, [1976/1977] 2020, p. 186).
} 
produtos imaginários do cérebro doente da governanta, projeções alucinadas, sintomáticas de sua frustação e de seus desejos sexuais recalcados" (FELMAN, [1976/1977] 2020, p. 187). O artigo provocou polêmica e dividiu a crítica em dois campos: a de fundo metafísico (em que a história é sobre fantasmas e a governanta aparece como uma figura moral em busca da salvação das crianças) e a crítica "freudiana", que tinha como modelo o trabalho de Wilson.

Recusando as duas correntes críticas e partindo da leitura lacaniana, Shoshana Felman propõe uma "outra volta da interpretação", uma outra forma de ler o texto literário: "menos assertiva, mais alusiva; menos paralisante, mais deslizante; menos na direção semântica e mais na direção da significância e da materialidade da letra" (BRANCO, 2020, p. 22). A sua maneira de trabalhar a relação entre psicanálise e literatura fez com que Shoshana Felman apresentasse uma inovação crítica para a época. Essa inovação é comparável à interpretação lacaniana do conto de Edgar Allan Poe, pois os dois autores se atentam ao "movimento da carta-letra, sublinhando que o seu sentido permanece oculto" (BRANCO, 2020, p. 22). Além disso, apesar de ter mudado de foco desde seus trabalhos sobre o trauma e o testemunho, o tema desenvolvido aqui antecipa, de certa forma, os seus livros posteriores.

Considerado pela própria autora como o seu texto mais provocador, ousado e lúdico, Le Scandale du corps parlant: Don Juan avec Austin, ou la Séduction em deux langues (1980) é uma obra de grande relevância para diferentes campos, entre eles, os estudos literários, a linguística, a teoria queer, performance studies, a psicanálise, a etnografia, a teoria política, o direito etc. Para que seja possível escrever sobre o escândalo do corpo, assim como sobre o escândalo da sedução, é preciso articular algo na encruzilhada de várias disciplinas e na própria encruzilhada de linguagens, considerando os pontos de encontros e desencontros (FELMAN, [2002] 2003). Essa tentativa de articulação não visa ao que é dito, mas ao que produz efeitos e atos, ao que está sendo realizado entre conhecimento e prazer, entre linguagens e corpos falantes.

Como indica o subtítulo, o livro centra-se na relação entre a teoria do performativo de Austin e a imagem de Don Juan. Nessa dupla ligação, tanto a teoria de Austin é uma chave de leitura da sedução e dos atos de fala de Don Juan (Molière) e de Don Giovanni (Mozart), quanto uma possibilidade de a literatura reinterpretar as noções filosóficas de Austin. Além desse encontro, a psicanálise surge para mostrar como a fala traz o corpo, colocando o inconsciente em questão (FELMAN, [2002] 2003).

Apesar dessa dimensão nuclear entre ato de fala e corpo, o livro publicado em 1980, em francês, foi traduzido para a língua inglesa e lançado nos Estados Unidos em 1984 com o título The Literary Speech Act: Don Juan with Austin, or Seduction in Two Langages. Sobre essa modificação no título, Butler (2003) aponta para a perda da palavra "corpo" entre as duas traduções. Em uma segunda edição da versão inglesa do livro, a tradução se reaproximou do título de 1980 (The Scandal of Speaking Body: Don Juan with Austin, or Seduction in Two Languages), dando relevo à relação crucial entre corpo e performativo. Além disso, Butler (2003) afirma que não haveria ato de fala sem corpo (nem corpo "fora" do ato de fala), ao mesmo tempo, o corpo seria um limite da intencionalidade no ato de fala. Tais atos são também formas de fazer, que demandam o corpo para instituir as realidades de que falam. Quando o corpo fala, ele imediatamente deixa de seguir as reivindicações feitas em prol da consciência. 
A relação produtiva do trabalho de Shoshana Felman com a noção de atos de fala já havia sido observada por Michel Pêcheux em seu artigo "Sobre a (des-) construção das teorias linguísticas". Para o filósofo, a autora "aborda seriamente as relações entre a teoria dos atos de fala e a psicanálise, de Freud a Lacan" (PÊCHEUX, 1998, p. 26). De acordo com Aline Azevedo Bocchi (2019), esse comentário abre uma via para uma abordagem discursiva do performativo:

Em sua análise do funcionamento da promessa em Don Juan, Felman (1980) parte de Austin para mostrar que o performativo comporta necessariamente sua falha: ele é, antes de mais nada, um "ato de falhar" ("l'acte de manquer"). A autora estabelece uma articulação entre a teoria dos atos de fala e a psicanálise, lançando mão da sedução constitutiva da complexa e escandalosa relação entre corpo e linguagem: o ato de fala, enquanto ato de um corpo falante, é sempre desconhecedor daquilo que produz, pois sujeito às determinações inconscientes. Felman se inscreve, portanto, em uma posição compatível com a análise de discurso, em seu modo de conceituar o sujeito discursivo. (BOCCHI, 2019, p. 23)

Além de assinalar as compatibilidades entre análise de discurso e esse livro, a citação destaca a importância do "ato de falhar", que se encontra presente tanto no performativo de Austin quanto no funcionamento da promessa em Don Juan. Sua sagacidade está em compreender que, tanto para psicanálise quanto para Austin, a questão sempre é a de um objetivo que falha na descoberta da satisfação intencionalmente procurada (BUTLER, 2003). A figura de Don Juan é nomeada como mito do escândalo, sendo também um mito da violação. Tal violação se daria em relação às promessas do personagem sedutor a várias mulheres, em particular, as promessas de casamento. O escândalo da sedução se liga, assim, ao escândalo da promessa quebrada.

As questões desse livro são relevantes e atuais, relacionando-se a outros contextos. Uma das ressonâncias da obra ocorre no livro The Juridical Unconscious: Trials and Traumas in the Twenthieth Century (2002), que discorre sobre o funcionamento dos corpos falantes nos tribunais. A retomada desse conceito em trabalhos posteriores indica, portanto, a importância de Le Scandale du corps parlant no percurso teórico e crítico da autora.

No ensaio "Educação e crise ou as vicissitudes do ensinar", Shoshana Felman ([1995] 2000, p. 13) parte da pergunta: "existiria uma relação entre trauma e pedagogia?" A autora aborda sobre a prática do testemunho na interação entre os campos pedagógico, literário, clínico e histórico. Além de tratar a questão sob uma perspectiva teórica, ela escreve também um testemunho de vida sobre os acontecimentos inesperados e os seus efeitos em uma classe na qual ela ministrou um curso sobre o tema. Ocorrido em 1984, "Literatura e testemunho: literatura, psicanálise e história" foi apresentado como um seminário de pós-graduação da Universidade de Yale. Na turma, havia cerca de 30 alunos, principalmente estudantes de letras. Devido à abrangência do (sub)título, o curso também atraiu pessoas de outras áreas, como filosofia, história, psicologia, sociologia, direito e medicina. 
No decorrer do curso e do ensaio, ela trabalha diversos testemunhos literários, filosóficos, psicanalíticos e históricos, narrando os efeitos que tais obras produziram na classe ${ }^{7}$. Sem dúvida, um dos efeitos mais notáveis ocorreu na passagem do texto escrito para o testemunho em vídeo de dois sobreviventes do Holocausto. Tratava-se de "uma coleção de testemunhos filmados - de relatos de vida autobiográficos dados por sobreviventes do Holocausto a entrevistadores voluntários, profissionalmente treinados, em sua maioria psicanalistas ou psicoterapeutas" (FELMAN, 2000, p. 59).

Ao assistirem ao depoimento de uma mulher que, aos 15 anos, sobreviveu à catástrofe da Segunda Guerra Mundial após sucessivas perdas familiares, os alunos inicialmente saíram em silêncio e comovidos da sessão. Eles logo passaram pelo inesperado "efeito reverso", falando sobre o assunto durante dias e semanas e superando o enquadramento e os limites da sala de aula: "aparentemente, não conseguiam falar de mais nada, independentemente de onde estivessem" (FELMAN, [1995] 2000, p. 60).

De minha parte, fui tomada de surpresa e fiquei preocupada com as dimensões críticas desta crise que a classe estava obviamente enfrentamento e que estava se agudizando. Dei-me conta, ao mesmo tempo, de que as consequências imprevisíveis da projeção eram, em si mesmas, uma intensificação psicanalítica da maneira pela qual a classe se sentia ativamente endereçada, não somente pelo vídeo, mas também pela intensidade e intimidade do envolvimento com o testemunho ao longo do curso. (FELMAN, [1995] 2000, p. 59).

Para solucionar essa crise, Shoshana Felman e o psicanalista Dori Laub ${ }^{8}$ concluíram que seria necessário que ela reassumisse sua autoridade de professora e trouxesse os alunos de volta à significação. Para tanto, seria realizado um endereçamento aos estudantes. Este foi dividido em duas partes. Na primeira, ela devolvia aos alunos, "em suas próprias palavras, a importância e o significado de suas reações". Na segunda, a autora tentaria "articular para eles uma visão integrada dos textos literários e dos vídeos - do significado de todos os textos juntos, numa relação com suas próprias reações" (FELMAN, [1995] 2000, p. 61).

Diante da experiência desse curso, Shoshana Felman atenta para a função do ensinar que, para ela, não deve ser apenas passar informações e conteúdos, mas fazer algo acontecer, testemunhar. Por esse motivo, é importante passar por uma crise para que haja uma transformação, uma mudança. Nesse ponto, o ensino de temas literários seria um meio de acessar uma dimensão crítica. Contudo, a autora também afirma que a tarefa do professor é "recontextualizar a crise e colocá-la outra vez em perspectiva, relacionar o passado e o futuro, reintegrando a crise, portanto, em um enquadre de significado transformado" (FELMAN, [1995] 2000, p. 68).

O inconsciente jurídico: Julgamentos e traumas no século XX ([2002] 2014) é considerado um dos trabalhos mais importantes e originais sobre a relação entre direito

\footnotetext{
${ }^{7}$ Entre os autores apresentados estavam Camus, Dostoiévski, Freud, Mallarmé, Paul Celan, além de dois testemunhos em fita de vídeo (Fortunoff Video Archive for Holocaust Testemonies at Yale).

${ }^{8}$ A autora explica que o psicanalista foi quem idealizou a produção do arquivo Fortunoff Video Archive for Holocaust Testemonies at Yale, assim como foi quem entrevistou os dois sobreviventes no vídeo usado no curso. Por esse motivo, ele acompanhou as sessões fílmicas.
} 
e literatura. Márcio Seligmann-Silva (2014, p.13) destaca a originalidade da obra. Para o autor, de modo diverso das abordagens que se restringem a analisar somente a literatura que se refere especificamente a temas jurídicos, "ao invés de se apoiar nos estudos literários para melhor compreensão da hermenêutica jurídica ou, ainda, de tratar das implicações jurídicas do campo literário e tradutório", Shoshana Felman suplanta essas concepções e procura aprofundar as camadas do encontro entre os dois campos. Para tanto, a autora investiga o elo oculto entre trauma e julgamento. A ligação torna-se mais aparente e visível devido a três ocorrências que estão associadas: a) a descoberta da psicanálise e, consequentemente, do trauma; b) os acontecimentos catastróficos ocorridos no século XX; e c) o uso inédito e constante dos instrumentos do direito para confrontar as feridas coletivas e os legados traumáticos das catástrofes históricas (FELMAN, [2002] 2014).

O livro mostra o funcionamento de dois julgamentos como paradigmas para a discussão do vínculo entre lei e trauma no século XX. Ambos foram nomeados como o “julgamento do século": o de Eichmann ${ }^{9}$ em Israel (1961) e o de O. J. Simpson ${ }^{10}$ em Los Angeles (1994-1995). A partir desses casos, ela estuda as relações entre o público e privado que os tribunais põem em cena, tanto alegórica quanto historicamente e que podem mostrar de forma amplificada o elo entre lei e trauma no século XX.

No caso de Eichmann, a justiça é convocada para responder muito mais do que a decisão sobre sua culpa ou inocência, devendo ser uma resposta à experiência histórica e traumática do Holocausto (FELMAN, [2002] 2014). Para problematizar a alegoria entre a consciência jurídica e o inconsciente jurídico, o desmaio do escritor e sobrevivente K. Zetnik durante o julgamento de Eichmann mostra uma outra dimensão do corpo da testemunha no tribunal, servindo como uma parábola do colapso da linguagem diante da relação entre trauma e lei.

No caso de O. J. Simpson, Shoshana Felman comenta que o tribunal começou com um julgamento individual de assassinato e logo se tornou um lugar de embate entre dois traumas coletivos: o da violência às mulheres e o racial (ser negro nos Estados Unidos). Em relação ao primeiro, que foi discutida nos tribunais, a autora faz referência à novela $A$ sonata a Kreutzer, de Liev Tolstói, em que "a violência de gênero intramatrimônio, a casa, o lar, a família são vistos como o local de um mal-estar - como Freud já havia revelado" (SELIGMANN-SILVA, 2014, p. 10). Apesar das suas diferenças, os dois julgamentos analisados tornaram-se "teatros de justiça". "Felman adentra a cena do tribunal, o 'teatro da justiça', para flagrar não o triunfo da razão e da justiça, mas sim o momento em que os traumas sociais são aí reencenados, postos em ação, e via de regra, reafirmados" (SELIGMANN-SILVA, 2014, p. 8, grifo do autor).

\footnotetext{
${ }^{9}$ Adolf Eichmann foi chefe da Seção de Assuntos Judeus no Departamento de Segurança de Hitler, sendo responsável pelo transporte de milhares de judeus aos campos de extermínio. Seu julgamento teve início no dia 11 de abril de 1961 e contou com centenas de testemunhas, tendo ampla repercussão midiática. Considerado culpado por diversos crimes, incluindo crimes contra a humanidade, ele foi condenado à morte e executado em 1962.

${ }^{10}$ O.J. Simpson, ex-jogador de futebol americano, foi acusado de duplo homicídio, de sua ex-mulher Nicole Brown e de seu amigo Ronald Goldman. Seu julgamento foi iniciado em setembro de 1994 e contou com centenas de testemunhas, tendo uma enorme cobertura midiática. Ele foi absolvido em 1995.
} 
O livro também aproxima a literatura de Franz Kafka à trajetória trágica de Walter Benjamin, especialmente seu suicídio na fronteira entre a Espanha e a França, que, por falta de um visto no passaporte, foi impedido de fugir da Gestapo. Assim como em "Diante da lei", em que um camponês tem sua entrada barrada diante da porta da lei até a hora de sua morte, "Benjamim sucumbiu na fronteira, na porta que poderia levá-lo à liberdade, pela simples ausência de um carimbo" (SELIGMANN-SILVA, 2014, p. 9). Tal relação entre literatura e vida se unifica para formar uma contra-leitura do significado do direito. "Dramas pessoais e literários explicitam o elemento traumático do inconsciente jurídico". Sendo assim, ao entrecruzar direito, psicanálise e literatura, ela "mostra-nos como a esfera subjetiva é esmagada pelo direito, na mesma medida em que recebe um local, um espaço, na literatura" (SELIGMANN-SILVA, 2014, p. 10), sem construir oposições maniqueístas como o inferno jurídico e o paraíso literário. Com o conceito de inconsciente jurídico, a autora coloca em questão uma reconfiguração do direito e de seus limites, atingindo o âmago da instituição jurídica.

Para finalizar, destaco que longe de esgotar o percurso intelectual dessa autora que produziu obras significativas para os mais variados campos do conhecimento, este perfil teve como objetivo abordar aspectos de sua vida e de seus principais textos.

\section{REFERÊNCIAS}

BOCCHI, Aline Fernandes de Azevedo. O funcionamento discursivo de campanhas sobre a violência no parto: testemunho, violência e silêncio. Linguagem em (Dis)curso - LemD, Tubarão, SC, v. 19, n. 1, p. 17-33, jan./abr. 2019.

BRANCO, Lucia Castello (Org). Shoshana Felman e a coisa literária: escrita, loucura, psicanálise. Belo Horizonte: Letramento, 2020.

_. Shoshana Felman e a coisa literária: live de lançamento da tradução de Shoshana Felman e a coisa literária. 2021. Disponível em: < https://www.youtube.com/watch?v=4gUyslwMiiA\&t=873s > Acesso em 19 fev. 2021.

BUTLER, Judith. Afterword. In: FELMAN, Shoshana. The Scandal of the speaking body: Don Juan with J.L. Austin, or Seduction in Two Languages. Stanford: Stanford University Press, 2003, p. 113-124.

FELMAN, Shoshana [1977]. Escrita e loucura: por que este livro. In: BRANCO, Lucia Castello (Org). Shoshana Felman e a coisa literária: escrita, loucura, psicanálise. Belo Horizonte: Letramento, 2020a. p. 39-60.

FELMAN, Shoshana [1995]. Educação e crise, ou as vicissitudes do ensino. In: NESTROVSKI, Arthur; SELIGMANN-SILVA, Márcio (Orgs). Catástrofe e representação. São Paulo: Escuta, 2000. p. 13-72.

FELMAN, Shoshana [1976/1977]. Henry James: loucura e interpretação. In: BRANCO, Lucia Castello (Org). Shoshana Felman e a coisa literária: escrita, loucura, psicanálise. Belo Horizonte: Letramento, 2020, p.185-292.

FELMAN, Shoshama [2002] O inconsciente jurídico: Julgamentos e traumas no século XX. São Paulo: EDIPRO, 2014.

FELMAN, Shoshana. [1977]. Só-depois In: BRANCO, Lucia Castello (Org). Shoshana Felman e a coisa literária: escrita, loucura, psicanálise. Belo Horizonte: Letramento, 2020b, p. 293-296.

FELMAN, Shoshana [2002]. The Scandal of the speaking body: Don Juan with J.L. Austin, or Seduction in Two Languages. Stanford: Stanford University Press, 2003. 
FELMAN, Shoshana. Writing and Madness: Literature/Philosophy/Psychoanalysis. Stanford: Stanford University Press, 2003.

PÊCHEUX, Michel. Sobre a (des-)construção das teorias linguísticas. Línguas e Instrumentos Linguísticos, Campinas, n. 2, p. 7-32, jul./dez.1998.

SELIGMANN-SILVA, Márcio. Prefácio. In: FELMAN, Shoshana [2002] O inconsciente jurídico: Julgamentos e traumas no século XX. São Paulo: EDIPRO, 2014.

Artigo recebido em: fev. de 2021.

Aprovado e revisado em: fev. de 2021.

Publicado em: fev. de 2021.

Para citar este texto:

RIBEIRO, Karine de Medeiros. Shoshana Felman. Entremeios [Revista de Estudos do Discurso, ISSN 2179-3514, on-line, www.entremeios.inf.br], Seção Perfil, Programa de PósGraduação em Ciências da Linguagem (PPGCL), Universidade do Vale do Sapucaí (UNIVÁS), Pouso Alegre (MG), vol. 23, p. 143-152, Edição especial/ 2020. DOI: http://dx.doi.org/10.20337/ISSN2179-3514revistaENTREMEIOSvol23pagina143a152 